\title{
A invaginação gengival e o fechamento ortodôntico de espaços de extrações: conduta clínica
}

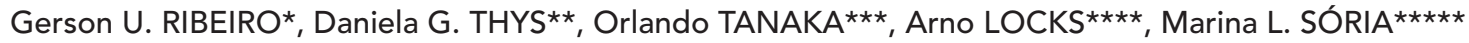

\begin{abstract}
Resumo
Este estudo tem como objetivo enfatizar a relação entre ortodontistas e periodontistas no intuito de melhorar os resultados do tratamento ortodôntico. A observação da formação de invaginações gengivais durante o fechamento do espaço de extrações pode gerar dificuldades na finalização e estabilização dos dentes adjacentes a estes espaços. A recidiva de dentes movimentados ortodonticamente pode ocorrer em virtude das fibras transeptais. O correto paralelismo radicular, uma fibrotomia criteriosa e a retenção imediata e adequada são procedimentos indispensáveis para se atingir a estabilidade nos casos tratados. Melhores resultados podem ser obtidos com a realização de fibrotomia supracrestal no local da extração prevenindo a recidiva nesta região.
\end{abstract}

Palavras-chave: Fechamento de espaço. Invaginação gengival. Fibras transeptais.

\section{INTRODUÇÃO}

Para muitos tratamentos ortodônticos são diagnosticadas e planejadas extrações de dentes permanentes, por falta de espaço para o alinhamento e nivelamento dos dentes, correção da linha mediana e posicionamento dos dentes nas bases ósseas. É comum a formação de fendas ou invaginações do tecido gengival durante a movimentação dos dentes adjacentes ao espaço destas extrações. $8,20,21$

A aparência clínica destas invaginações varia de pequena prega na gengiva inserida até uma fenda profunda que se estende através da papila interdental da superfície vestibular até a lingual. Muitas questões têm sido discutidas com relação às causas e tratamentos mais indicados para estas alterações, mas a maioria dos autores não chegou a nenhuma conclusão precisa. O presente estudo discutirá as causas e possíveis tratamentos para as invaginações gengivais formadas durante o fechamento ortodôntico de espaços.

* Mestre e doutor em Ortodontia; Professor adjunto da disciplina de Ortodontia FO-UFSC; Professor do curso de especialização de Ortodontia FO-UFSC; Diplomado pelo Board Brasileiro de Ortodontia.

** Cirurgiã-dentista graduada pela Faculdade de Odontologia UFSC; Estagiária da Disciplina de Ortodontia FO-UFSC; Aluna do Curso de Mestrado em Ortodontia PUCPR.

*** Mestre e doutor em Ortodontia; Professor titular da disciplina de Ortodontia PUC-PR; Coordenador do Curso de Mestrado em Ortodontia PUCPR; Diplomado pelo Board Brasileiro de Ortodontia.

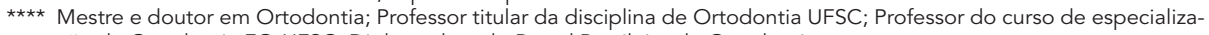
ção de Ortodontia FO-UFSC; Diplomado pelo Board Brasileiro de Ortodontia. $\star \star \star \star \star$ Aluna do curso de mestrado em Ortodontia PUC-RS 


\section{DISCUSSÃO}

A causa precisa das invaginações gengivais não é totalmente conhecida, ocorrem mais comumente em pacientes sob tratamento ortodôntico com o fechamento dos espaços das extrações dentárias e, podem ser conseqüência da interrupção da continuidade do sistema de fibras gengivais, remodelamento ósseo com a destruição das corticais ósseas, cicatrização do alvéolo e/ou da movimentação das raízes. Ou ainda, pelo fato das fibras deslocarem-se ao invés de serem remodeladas, tendo como resultado o acúmulo de tecido gengival na região ${ }^{2}$.

Tem sido sugerido que o remodelamento ósseo que ocorre depois das extrações é causa da formação das invaginações em virtude da lâmina própria da gengiva inserida, que está saudável, fundir-se com o periósteo do osso subjacente, e então qualquer alteração no contorno ósseo refletir-se-á na mesma ${ }^{11}$. Além disso, o suporte dento-alveolar fica reduzido durante a movimentação dos dentes, como resultado de reabsorção radicular ${ }^{12,14,16}$ e perda de osso proximal $1,12,23,28$.

A formação desta alteração pode estar relacionada às diferenças de espessura óssea do rebordo, altura da crista, capacidade de remodelamento e espessura e diâmetro da gengiva inserida. Por isso, é importante observar o paciente antes da extração para estabelecer se a altura da crista óssea ou se o tempo que se levará para retrair o canino serão fatores críticos na determinação de alterações no contorno ósseo próximos a crista alveolar ${ }^{5}$.

$\mathrm{Na}$ maioria dos casos, o movimento de retração do canino é que empurra a gengiva distalmen$\mathrm{te}^{24}$, havendo a formação da invaginação na distal deste dente, enquanto que na mesial se observa a formação de uma mancha avermelhada de forma triangular ${ }^{13}$.

A relação entre inclinação das raízes dos dentes adjacentes ao espaço do dente extraído e a formação de invaginações não tem tanta influência na formação da alteração ${ }^{1,5}$, sendo que o fator determinante é o próprio movimento de aproximação dos dentes ${ }^{5}$. Tentativas de sobrecorreção das raízes não permitem que as coroas se toquem, deixando um espaço entre as mesmas, além de não resolver o problema da recidiva no espaço da extração e formação das alterações gengivais ${ }^{10}$.

Estudos histológicos dos tecidos duros e moles da região de exodontias, seguidas do fechamento do espaço, foram realizados com o intuito de verificar diferenças entre o fechamento precoce ou tardio (antes ou após a cicatrização do alvéolo) dos espaços das extrações. Mostraram que, no fechamento tardio, quando o alvéolo já está cicatrizado, há uma maior tendência de formação de invaginações gengivais do que no grupo em que os espaços foram fechados imediatamente após a extração. Indicando que o fechamento de espaços deve ser iniciado o quanto antes $^{6}$. As invaginações gengivais ocorrem mais e são mais severas no arco inferior ${ }^{5,21}$, parecendo ter implicações clínicas na manutenção da saúde gengival.

O tecido ósseo de suporte também sofre alterações em virtude das extrações e movimentação ortodôntica para fechamento dos espaços, sendo que a distância entre a junção cemento-esmalte e a margem óssea, na mesial do primeiro molar adjacente a um dente extraído tardiamente, é maior do que a distância observada no lado de um dente enucleado ${ }^{27}$. É provável que aconteça perda de osso marginal mesial e distal aos espaços das extrações, diminuição da altura da crista óssea interdental, e aumento no tempo para o fechamento dos espaços nesses casos ${ }^{28}$.

A gengivite resultante da inadequada higienização no local das invaginações parece diminuir a recidiva entre os dentes aproximados, devido ao fato de que a inflamação implica em destruição das fibras gengivais desorientadas e anatomicamente deformadas, fazendo com que as novas fibras formadas sejam mais compatíveis com a nova posição dos dentes ${ }^{8}$. 
Muitos autores afirmam que a invaginação gengival tem papel ativo nas recidivas da posição dos dentes, mas na verdade a etiologia (especialmente reabertura do espaço) permanece indeterminada ${ }^{19}$. As possíveis causas incluem inclinação e intercuspidação dos dentes e distorção das fibras supracrestais. Estudos histológicos sugerem que decorre um considerável tempo antes que o osso e os tecidos gengivais se reorganizem seguindo a movimentação ortodôntica ${ }^{7,9}$. A compressão das fibras transeptais ${ }^{9,18}$ também têm sido relatada como causa na reabertura dos espaços das extrações ${ }^{4,8,17,18}$. Já Circuns $^{5}$ não encontrou em seu estudo nenhuma correlação consistente entre a formação da invaginação gengival e a reabertura dos espaços das extrações.

Histologicamente as áreas das invaginações demonstraram epitélio hiperplásico e com metabolismo aumentado, bem como intensa produção de glicosaminoglicanas no tecido conjuntivo circundante e a perda de colágeno nas mesmas regiões. Houve evidência de remodelamento, mais do que de reabsorção óssea e o estímulo gerado pelas forças ortodônticas foi responsável pela reação de tecido hiperplasiado ${ }^{22}$.

Também sob observações microscópicas notou-se profunda proliferação, hiperqueratinização e pérola de queratina isolada no tecido conjuntivo. Riqueza de células e tecido conjuntivo frouxo com baixa densidade de fibras foram dominantes na camada subepitelial. A camada periosteal apresentou múltiplas fibras, algumas com direção paralela outras com arranjo reticular espalhadas com muitos vasos sanguíneos e poucas células inflamatórias no tecido mole. $\mathrm{O}$ osso se mostrou reabsorvido na área mésio-palatal do primeiro molar (direção de movimento do dente) e provavelmente a inflamação não teve influência na reabsorção apresentada pelo dente e tecido ósseo ${ }^{25}$.

A preocupação a cerca das invaginações gengivais é a manutenção da saúde periodontal na área afetada. É sugerido, que a invaginação gengival, predispõe direta ou indiretamente à formação de pobres contatos interproximais, acúmulo de placa e gengivite. Sua formação e persistência durante e após a movimentação ortodôntica pode ter um efeito adverso na saúde periodonta $1^{5}$, além é claro do comprometimento estético.

As invaginações podem persistir por até 5 anos após o término do tratamento ortodôntico e eventualmente, o processo natural pode eliminar o excesso gengival entre os dentes aproximados porém aguardar tal ocorrência imprevisivel não é justificável ${ }^{8}$. Mesmo que nenhuma correlação possa ser estabelecida entre a reabertura dos espaços e a presença de invaginações, Circuns ${ }^{5}$ ressalta que as alterações na gengiva podem indicar sua remoção cirúrgica, muito embora, outros autores afirmem que sua remoção cirúrgica só está indicada quando houver a presença de hiperplasia gengival persistente e comprometimento estético do contorno gengival ${ }^{15}$.

O completo fechamento dos espaços das extrações com paralelismo radicular dos dentes adjacentes associado à contenção individualizada são fatores significativos de redução da recidiva nesta região. Mesmo assim, para obter-se estética e maior estabilidade em termos periodontais entre os dentes aproximados e adjacentes aos espaços das extrações, deve-se fazer a ressecção cirúrgica das fibras supragengivais e remoção do excesso de tecido gengival dos dentes movimentados a uma considerável distância, como no caso de extrações de dentes, favorecendo a estabilidade dos dentes $\operatorname{aproximados}^{13,20}$.

\section{CASO CLÍNICO}

Indivíduo do gênero feminino de 16 anos de idade, tratado ortodonticamente com extração dos quatro primeiros pré-molares. Os espaços das extrações estavam totalmente fechados, porém devido à formação de invaginação gengival entre os caninos e segundos pré-molares, nas quatro hemiarcadas (Fig. 1 a 7), planejou-se a gengivoplastia 


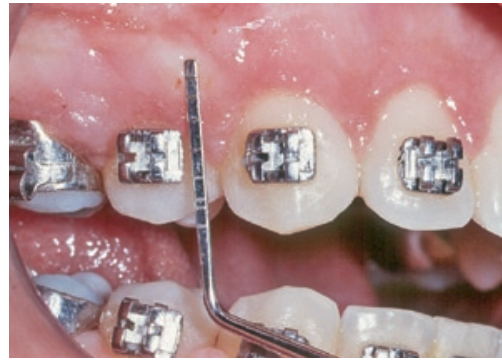

FIGURA 1 - Sonda periodontal e a profundidade da bolsa formada entre os dentes 13 e 15.

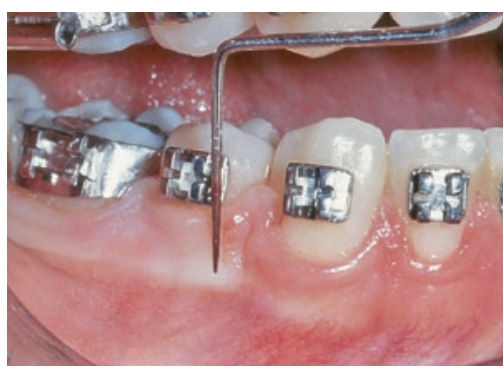

FIGURA 4 - Sonda periodontal e a profundidade da bolsa formada entre 043 e 45 .

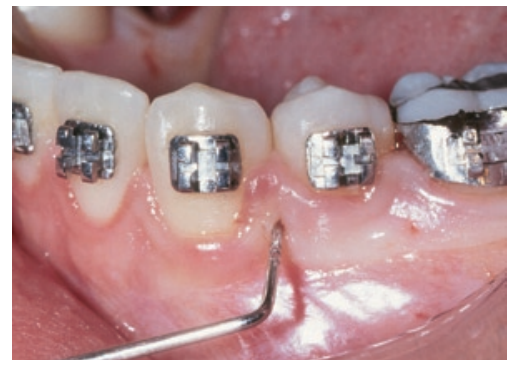

FIGURA 7 - Sonda periodontal e a extensão vestibulo-lingual da bolsa formada entre o 33 e 35 .

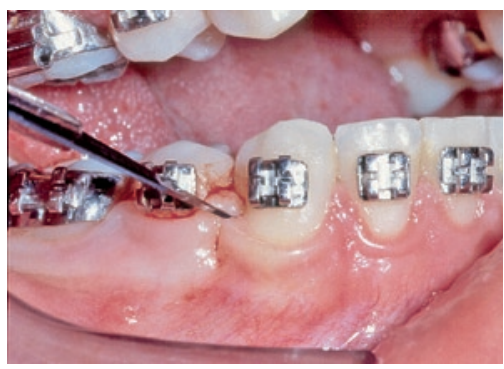

FIGURA 10 - Cirurgia: continuação da desinserção e remoção do excesso de tecido gengival.

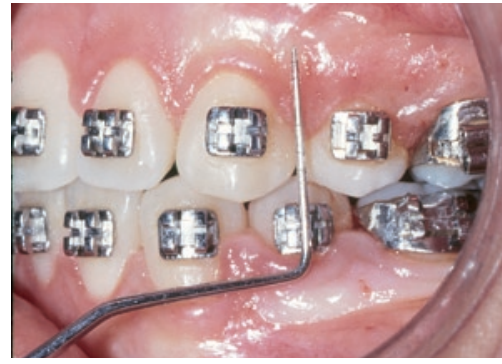

FIGURA 2 - Sonda periodontal e a profundidade da bolsa formada entre os dentes 23 e 25 .

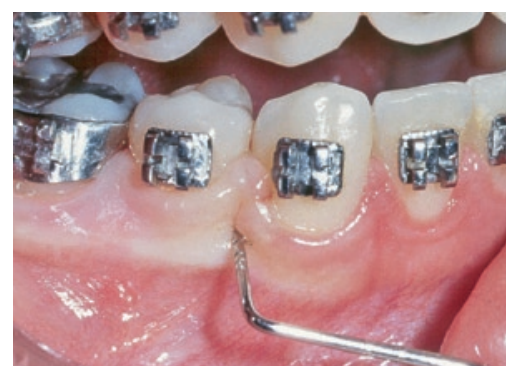

FIGURA 5 - Sonda periodontal e a extensão vestilo lingual da bolsa formada entre 043 e 45 .

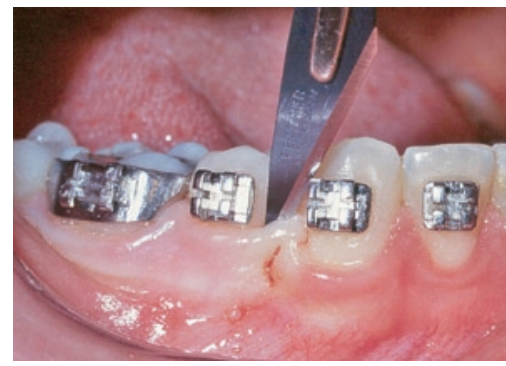

FIGURA 8 - Cirurgia: desinserção intra-sulcular das fibras supra-alveolares, com bisturi (lâmina 12). A incisão se deu entre o canino e segundo pré-molar até o contato com a crista óssea alveolar.

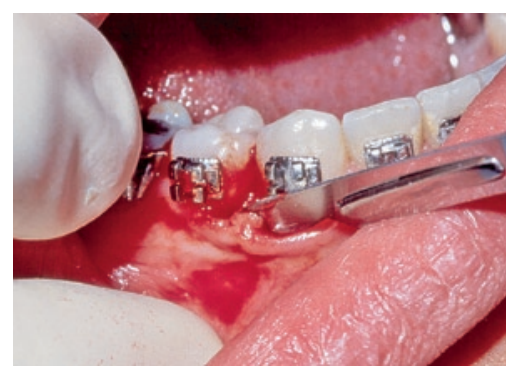

FIGURA 11: Cirurgia: descolamento do tecido gengival. Então foi feito debridamento do tecido de granulação existente entre o canino e segundo pré-molar com auxílio de um pedaço de fio dental.

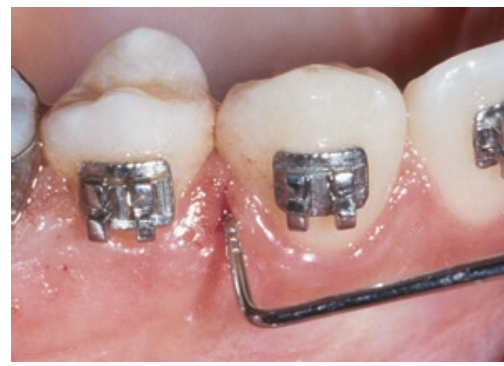

FIGURA 3 - Sonda periodontal e a extensão ves tibulo-lingual da bolsa formada entre os dentes 13 e 15.

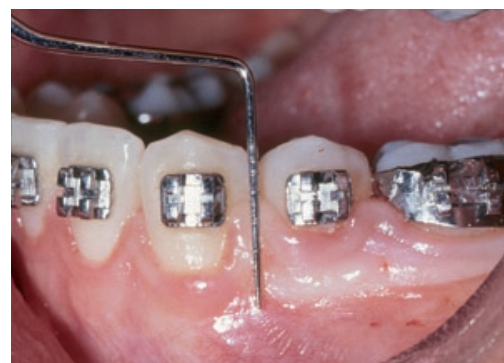

FIGURA 6 - Sonda periodontal e a profundidade da bolsa formada entre o 33 e 35 .

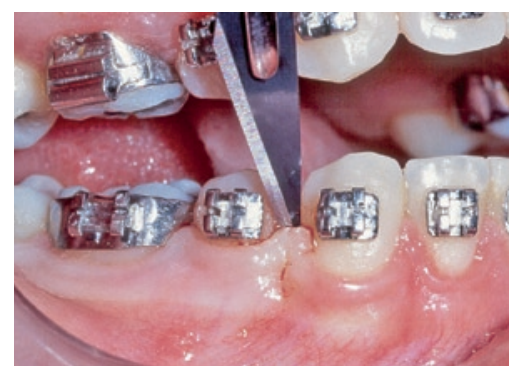

FIGURA 9 - Cirurgia: extensão da incisão intra-sulcular para o segundo pré-molar, que ao início do tratamento apresentava-se girado, de maneira a evitar a recidiva. A incisão é realizada intra-sulcularmente até o contato com a crista óssea alveolar, removendo a inserção das fibras supra-alveolares ao redor do dente (esta incisão foi realizada em ambos segundos pré-molares inferiores). 

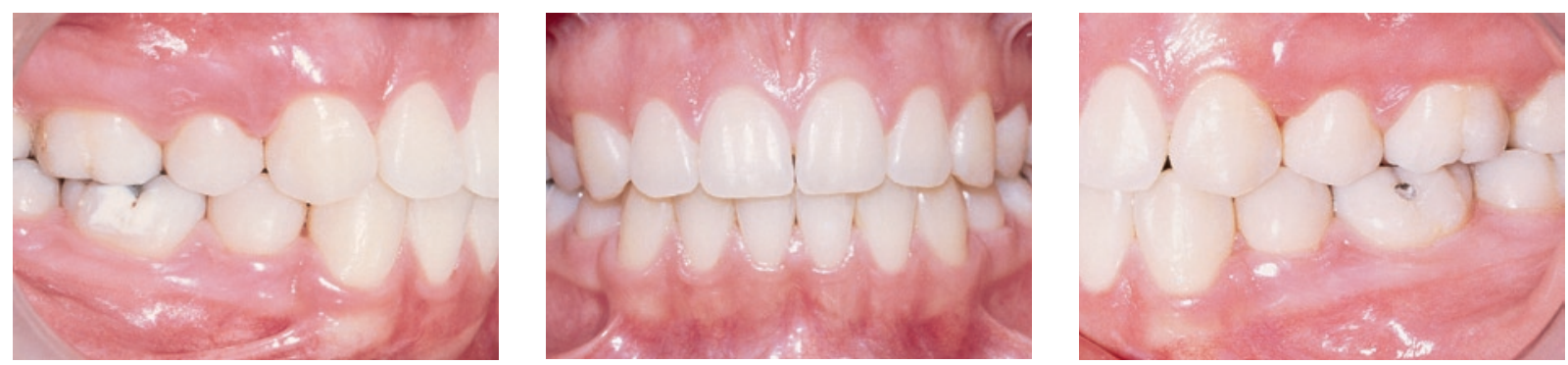

FIGURA 12, 13, 14 - Aspecto final 30 dias após a cirurgia. Pode-se observar a completa cicatrização e formação de papila gengival normal em condições satisfatórias.

para a remoção do excesso de tecido gengival e normalização da pseudobolsa presente, ocasião em que foi realizada a desinserção das fibras supra-alveolares ao redor dos segundos pré-molares inferiores, com giroversão ao início do tratamento, visando a estabilidade. O caso é descrito nas figuras 1 a 18.

\section{CONCLUSÕES}

De acordo com o presente estudo, conclui-se que as invaginações gengivais:

- estão presentes em ambas as arcadas, porém são encontradas com maior freqüência e severidade na arcada inferior;

- sua etiologia e formação, embora imprecisa, parece estar relacionada ao deslocamento das fibras ao invés do remodelamento das mesmas;

- quando o alvéolo já está cicatrizado, há uma maior tendência de formação de invaginações gengivais, dessa forma o fechamento dos espaços deve ser iniciado o quanto antes;

- podem persistir por longos períodos pós-contenção;

- não parece ter relação direta com a reabertura dos espaços das extrações;

- é indicada a remoção cirúrgica, pois sua persistência durante e após a movimentação ortodôntica pode ter efeito adverso na saúde periodontal, com danos irreversíveis, além é claro do comprometimento estético.

\section{The gengival invagination and the orthodontic space closure of extractions: a clinical conduct \\ Abstract}

The objetive of this study was to emphasize the orthodontists and periodontists relationship to enhance periodontal tissue during finishing and maintenance of orthodontic treatment results. The observation of the gingival tissue clefts during the extraction spaces closure phase can generate difficulties to finishing and stabilization of the adjacent teeth to the extraction sites. The relapse of the orthodontically moved teeth can probably be caused by the transeptal fibers. The correct root parallelism, a criterious fibertomy and immediate and adequate retention are indispensable procedures to achieve orthodontic treated cases stability. Better results are obtained with supracrestal fibertomy in severe rotated teeth and gingival hyperplasia in extraction sites preventing relapse in these region.

Key words: Spaces closure. Gingival clefts. Transeptal fibers. 


\section{REFERÊNCIAS}

1. ARTUN J.; KOKICH V. G.; OSTERBERG S. K. Long-term effect of root proximity on periodontal health after orthodontic treatment. Am J Orthod Dentofacial Orthop, St. Louis, v. 91, no. 2, p. 125-130, 1987

2. ATHERTON, J. D. The gingival response to orthodontic tooth movement, Am J Orthod, St. Louis, v. 58, no. 2, p. 179-186, 1970.

3. BAXTER D. H. The effect of orthodontic treatment on alveolar bone adjacent to the cemento-enamel junction. Angle Orthod, Appleton, v. 37, no. 1, p. 35-47, 1967

4. BRAIN, W. E. The effect of surgical transsection of free gingival fibers on the regression of orthodontically rotated teeth in the dog. Am J Orthod, St. Louis, v. 55, no. 1, p. 50-70, 1969.

5. CIRCUNS, A. L. R.; TULLOCH, J. F. C. Gingival invagination in extraction sites of orthodontic patients: their incidence, effects on periodontal health, and orthodontic treatment. Am J Orthod, St. Louis, v. 83, no. 6, p. 469-476, 1983.

6. DIEDRICH, P.; WEHRBEIN, H. Orthodontic retration into recent and healed extraction sites. A histologic study. J Orofac Orthop, Munich, v. 58, no. 2, p. 90-99, 1997

7. EDWARDS, J. G. A study of the periodontium during orthodontic rotation of teeth. Am J Orthod, St. Louis, v. 54, no. 6 , p. 441-461, 1968.

8. EDWARDS, J. G. The prevention relapse in extraction cases. Am J Orthod, St. Louis, v. 60, no. 2, p. 128-144, 1971.

9. ERIKSON, B. E.; KAPLAN, H.; AISENBERG, M. S. Orthodontics and transeptal fibers. Am J Orthod, St. Louis, v. 31, p. 1-20, 1945.

10. HATASAKA, H. R. A radiographic study of roots in extration sites. Angle Orthod, Appleton, v. 46, no. 1, p. 64-68, 1976.

11. HEANEY, T. G.; ATHERNON, J. D. Periodontal problems associated with cirurgical exposure of erupted teeth. Br J Orthod, London, v. 3, no. 2, p. 79-84, 1976.

12. KENNEDY, D. B.; JOONDEPH, D. R.; LITTLE, R. M. The effect of extraction and Orthodontic treatment on dentoalveolar support. Am J Orthod, St. Louis, v. 84, no. 3, p. 183-190, 1983.

13. McCOLLUM, A. G. H.; PRESTON, B. P. Maxillary canine retraction, periodontal surgery, and relapse. Am J Orthod, St. Louis, v. 78 , no. 6, p. 610-622, 1980.

14. McLAUGHLIN, K. D. Quantitative determination of root resorp tion during orthodontic treatment. Am J Orthod, St. Louis, v. 50 , p. 143,1964

15. NETO, J. V.; MOTA, D. M.; MONINI, A. C.; RUIZ, L. F. N. Significado da invaginação gengival em locais de extração dentária após o fechamento ortodôntico dos espaços. R Dental Press Ortodon Ortop Facial, Maringá, v. 7, n. 3, p. 95-103, maio/ jun. 2002.
16. NEWMAN, W. G. Possible etiological factors in external root resorption. Am J Orthod, St. Louis, v. 67, no. 5, p. 522-538, 1975

17. NORTON, L. A. Periodontal considerations in orthodontic treatment. Dent Clin North Am, Philadelphia, v. 25, no. 1, p. 117-129, 1981.

18. PARKER, G. R. Transeptal fibers and relapse following bodily retartion of teeth: a histologic study. Am J Orthod, St. Louis, v. 61, no. 4, p. 331-344, 1972.

19. REITAN, K. Principles of retention and avoidance of post treatment relapse. Am J Orthod, St. Louis, v. 55, no. 6, p. 776-790, 1969

20. RIBEIRO, G. L. U.; TANAKA, O. M.; BOLOGNESE, A. M. Considerações periodontais na finalização e estabilidade do tratamento ortodôntico em casos de giroversões e nos espaços das extrações. R SBO, Rio de Janeiro, v. 2, n. 3, p. 81-88, 1993.

21. ROBERTSON, P. B.; SCHULTZ, L. D.; LEVY B. M. Occurrence and distribution of interdental gingival clefts following orthodontic movement into bicuspid extraction sites. J Periodontol Birmingham, v. 48, no. 4, p. 232-235, 1977.

22. RONNERMAN, A : THILANDER, B.; HEYDEN, G. Gingival tissue reactions to orthodontic closure of extration sites. Histollogic and histochemical studies. Am J Orthod, St. Louis, v. 77, no. 6, p. 620-625, 1980.

23. SJÖLIEN, T.; ZACHRISSON, B. U. Periodontal bone support and tooth length in orthodontically treated and untreated persons. Am J Orthod, St. Louis, v. 64, no. 1, p. 28-37, 1973.

24. VECERE, J. W. Extraction space closure stability following canine retraction and periodontal surgery. Am J Dentofacial Orthop, St. Louis, v. 84, no. 1, p. 89-90, 1983.

25. WEHRBEIN, H.; BAUER, W.; DIEDRICH, P. R. Gingival invagination after space closure: a histologic study. Am J Orthod Dentofacial Orthop, St. Louis, v. 108, no. 6, p. 593-598, 1995.

26. WEHRBEIN, H.; FUHRMANN, R.; ANDREAS, A.; DIEDRICH, P. The significance of gingival invagination in orthodontic space closure. A clinico-radiological study. Fortschr Kieferorthop, Munich, v. 54, no. 6, p. 231-236, 1993.

27. WISTH, P. J. Periodontal status of neighboring teeth after orthodontic closure of mandibular extraction sites. Scand J Dent Res, Copenhagen, v. 83, no. 6, p. 307-313, 1975.

28. ZACHRISSON, B. U.; ALNAES, L. Periodontal condition in orthodontically treated and untreated individuals. II. Alveolar bone loss: radiographic findings. Angle Orthod, Appleton, v. 44 , no. 1 , p. $48-55,1974$

\section{Endereço para correspondência}

Daniela G. Thys

Rod. Admar Gonzaga 1447, apto 204. Itacorubi

Florianópolis. SC. 88034-000

daniela_thys@yahoo.com.br 